\title{
The disappearing mammal fauna of northern Australia: context, cause, and response
}

John C. Z. Woinarski, ${ }^{1,2,3}$ Sarah Legge, ${ }^{3,4,5}$ James A. Fitzsimons, ${ }^{6,7}$ Barry J. Traill, ${ }^{8}$ Andrew A. Burbidge,,${ }^{9,10}$ Alaric Fisher, ${ }^{1,3}$ Ron S. C. Firth, ${ }^{2,11}$ lain J. Gordon, ${ }^{12}$ Anthony D. Griffiths, ${ }^{1}$ Christopher N. Johnson, ${ }^{13}$ Norm L. McKenzie, ${ }^{9}$ Carol Palmer, ${ }^{1}$ Ian Radford,${ }^{14}$ Brooke Rankmore, ${ }^{2}$ Euan G. Ritchie, ${ }^{7}$ Simon Ward, ${ }^{1}$ \& Mark Ziembicki ${ }^{1,15}$

${ }^{1}$ Department of Natural Resources, Environment, The Arts and Sport, PO Box 496, Palmerston, Northern Territory 0831, Australia

${ }^{2}$ School of Environmental Research, Charles Darwin University, Casuarina, Northern Territory 0909, Australia

${ }^{3}$ North Australian Biodiversity Hub, Charles Darwin University, Casuarina, Northern Territory 0909, Australia

${ }^{4}$ Australian Wildlife Conservancy, Mornington Wildlife Sanctuary, PMB 925 Derby, Western Australia 6728, Australia

${ }^{5}$ Research School of Biology, College of Medicine, Biology and Environment, The Australian National University, Canberra, ACT 0200, Australia

${ }^{6}$ The Nature Conservancy, 60 Leicester Street, Carlton, Victoria 3053, Australia

${ }^{7}$ School of Life and Environmental Sciences, Deakin University, Burwood, Victoria 3125, Australia

${ }^{8}$ Pew Environment Group, 2 Treehaven Way, Maleny, Queensland 4552, Australia

${ }^{9}$ Department of Environment and Conservation, PO Box 51, Wanneroo, Western Australia 6946, Australia

${ }^{10}$ Current address: 87 Rosedale Street, Floreat, Western Australia 6014, Australia

${ }^{11}$ ENV. Australia Pty Ltd, PO Box 7480, Cloisters Square Perth, Western Australia 6850, Australia

12 The James Hutton Institute, Mylnefield, Ivergowrie, Dundee DD2 5DA, UK

${ }^{13}$ School of Zoology, University of Tasmania, Private Bag 5, Hobart, Tasmania 7001, Australia

${ }^{14}$ Department of Environment and Conservation, PO Box 942, Kununurra Western Australia 6743, Australia

${ }^{15}$ School of Marine and Tropical Biology, James Cook University, PO Box 6811, Cairns, Queensland, 4870, Australia

\section{Keywords}

Cats; extinction processes; grazing; fire; mammals; protected areas.

\section{Correspondence}

John C. Z. Woinarski, Department of Natural Resources, Environment, The Arts and Sport, PO Box 496, Palmerston, Northern Territory 0831, Australia.

Tel: +61 (0)8 89955001;

fax: +61 (0)8 89955099 .

Email: john.woinarski@nt.gov.au

Received

10 September 2010

Accepted

18 January 2011

Editor

Corey Bradshaw

doi: 10.1111/j.1755-263X.2011.00164.x

\begin{abstract}
This article provides a context to, attempts an explanation for, and proposes a response to the recent demonstration of rapid and severe decline of the native mammal fauna of Kakadu National Park. This decline is consistent with, but might be more accentuated than, declines reported elsewhere in northern Australia; however, such a comparison is constrained by the sparse information base across this region. Disconcertingly, the decline has similarities with the earlier phase of mammal extinctions that occurred elsewhere in Australia. We considered four proximate factors (individually or interactively) that might be driving the observed decline: habitat change, predation (by feral cats), poisoning (by invading cane toads), and novel disease. No single factor readily explains the current decline. The current rapid decline of mammals in Kakadu National Park and northern Australia suggests that the fate of biodiversity globally might be even bleaker than evident in recent reviews, and that the establishment of conservation reserves alone is insufficient to maintain biodiversity. This latter conclusion is not new; but the results reported here further stress the need to manage reserves far more intensively, purposefully, and effectively, and to audit regularly their biodiversity conservation performance.
\end{abstract}

\section{Introduction}

\section{North Australian mammal declines: a case study from Kakadu}

In one of Australia's largest, best resourced, and most biodiversity-rich conservation reserves (Kakadu National
Park), situated within a region subject to relatively little human modification, a monitoring program has demonstrated a rapid and severe decline in the native mammal fauna over the last decade (Woinarski et al. 2010). That decline appears to be unrelated to any short-term climatic variation. 
Table 1 Summary table showing changes in abundance of small-medium sized mammal species (excluding bats) reported from the Kakadu monitoring program (modified from Woinarski et al. 2010). $n$ refers to the total number of quadrats from which reported (only species recorded from five or more quadrats are listed); abundance is the mean (with standard error in brackets) for the 136 quadrats; and Z is the Z-score from Wilcoxon matched pairs test

\begin{tabular}{|c|c|c|c|c|c|c|}
\hline Scientific name & Common name & $n$ & Abundance 2001-04 & Abundance 2007-09 & Z & $P$ \\
\hline Tachyglossus aculeatus & Short-beaked echidna & 9 & $0.04(0.02)$ & $0.02(0.01)$ & 0.63 & 0.53 \\
\hline Antechinus bellus & Fawn antechinus & 27 & $0.40(0.13)$ & $0.04(0.02)$ & 2.92 & 0.003 \\
\hline Dasyurus hallucatus & Northern quoll & 39 & $0.49(0.11)$ & $0.02(0.02)$ & 4.27 & $<0.001$ \\
\hline Planigale maculata & Common planigale & 17 & $0.12(0.05)$ & $0.04(0.02)$ & 1.26 & 0.21 \\
\hline Pseudantechinus bilarni & Sandstone antechinus & 18 & $0.10(0.05)$ & $0.13(0.05)$ & 0.57 & 0.57 \\
\hline Isoodon macrourus & Northern brown bandicoot & 36 & $0.34(0.09)$ & $0.04(0.03)$ & 3.39 & $<0.001$ \\
\hline Trichosurus vulpecula & Common brushtail possum & 8 & $0.07(0.03)$ & $0.01(0.01)$ & 2.20 & 0.02 \\
\hline Petropseudes dahli & Rock ringtail possum & 8 & $0.02(0.01)$ & $0.04(0.02)$ & 0.73 & 0.46 \\
\hline Melomys burtonis & Grassland melomys & 26 & $0.32(0.13)$ & $0.40(0.17)$ & 0.47 & 0.64 \\
\hline Pseudomys delicatulus & Delicate mouse & 8 & $0.04(0.02)$ & 0 & 2.02 & 0.04 \\
\hline Pseudomys nanus & Western chestnut mouse & 10 & $0.07(0.03)$ & $0.02(0.02)$ & 1.30 & 0.19 \\
\hline Rattus colletti & Dusky rat & 5 & $0.84(0.48)$ & 0 & 1.60 & 0.11 \\
\hline Rattus tunneyi & Pale field-rat & 34 & $0.70(0.19)$ & $0.04(0.02)$ & 3.62 & $<0.001$ \\
\hline Zyzomys argurus & Common rock-rat & 57 & $0.82(0.22)$ & $0.24(0.06)$ & 2.92 & 0.003 \\
\hline Zyzomys maini & Arnhem rock-rat & 16 & $0.19(0.13)$ & $0.09(0.03)$ & 0.04 & 0.97 \\
\hline Total individuals & & & $4.68(0.69)$ & $1.17(0.22)$ & 6.14 & $<0.001$ \\
\hline Species richness & & & $1.34(0.11)$ & $0.61(0.07)$ & 5.37 & $<0.001$ \\
\hline
\end{tabular}

The monitoring program and its results are considered in detail elsewhere (Woinarski et al. 2010), and only a brief description is provided here. It comprises more than 100 permanently marked quadrats situated representatively across the $20,000-\mathrm{km}^{2}$ park, including many remote quadrats accessible only by a helicopter. The program was established for vegetation monitoring in 1995 (Edwards et al. 2003; Russell-Smith et al. 2009), with the intention of repeat sampling at 5-year intervals. Sampling of vertebrate fauna was commenced in 1996. A total of 142 quadrats were sampled for vertebrate fauna in the period 2001-2004 and those same quadrats were sampled again in the period 2007-2009. Sampling comprised a systematic and consistent protocol of live trapping (over three nights) and censusing in a $50 \mathrm{~m} \times 50 \mathrm{~m}$ quadrat (or 1 ha quadrat for bird observations). There were some changes in the abundance of individual plant, reptile, and bird species (Edwards et al. 2003; Russell-Smith et al. 2009), but the most striking result has been the decline of many small-medium sized native mammal species (Table 1). Over this 5- to 8-year period, the number of mammal species per quadrat decreased by $54 \%$, and the number of mammal individuals recorded per quadrat decreased by $75 \%$. Since 1996, the number of "mammal empty" quadrats increased from $10 \%$ to $58 \%$. This mammal decline extends and accentuates a pattern reported for Kakadu for the period 1986-1999 (Woinarski et al. 2001 ): indeed, some mammal species common in Kakadu 30-40 years ago (e.g. brush-tailed rabbit-rat, Conilurus penicillatus; northern brush-tailed phascogale, Phascogale pirata; black-footed tree-rat, Mesembriomys gouldii: Calaby 1973) are not listed in Table 1 because they were unrecorded or recorded too infrequently in this recent monitoring period.

\section{Context for the north Australian mammal declines}

A fundamental context for considering any contemporary pattern of mammal decline in Australia is the nation's recent history of mammal extinctions. Since European settlement of the continent in 1788, 22 native mammal species have become extinct (Morton 1990; Johnson 2006; McKenzie et al. 2007; Burbidge et al. 2008). Another eight species that occurred widely across the Australian mainland persist now only as savior populations on a small number of islands and, in some cases, as translocated populations within intensively managed fenced areas (Burbidge et al. 2008). The extinctions comprised $6 \%$ of Australia's marsupial species and 14\% of its native rodent species; and represent about one-third of all mammal species that have become extinct worldwide over the last 500 years (Baillie 1996). The Australian mammal extinctions mostly occurred during 1890-1950 before modern society assumed responsibility for their conservation, when there was a broadly held perception that the vastness of the Australian interior would provide robust refuge, and when there was little scientific knowledge or public interest in areas remote from the coastal population centers (Finlayson 1945, 1961). These 
extinctions are now largely viewed as a past event, and an unfortunate and unpredicted consequence of factors introduced with European settlement.

Many retrospective analyses have demonstrated that the likelihood of extinction varied with species' morphological, life history, taxonomic, and ecological characteristics, and was geographically uneven (Burbidge 8 McKenzie 1989; Morton 1990; Short \& Smith 1994; Smith \& Quin 1996; Cardillo \& Bromham 2001; Johnson 2006; Chisholm \& Taylor 2007; McKenzie et al. 2007; Burbidge et al. 2008; Johnson \& Isaac 2009). Mammal extinctions in Australia were more likely in arid and semiarid regions (far from human population centers), for mediumsized species, for species not associated with rocky areas, and for bandicoots (Peramelidae), larger rodents (Muridae), smaller macropods (Potoroidae, Macropodidae), and larger dasyurids (Dasyuridae). The main driver of these extinctions has been contested, but there is strong evidence implicating the two introduced predatory mammals (the red fox, Vulpes vulpes and cat, Felis catus), with some evidence suggesting an independent or synergistic impact of habitat change associated with the spread of livestock (Morton 1990; Short \& Smith 1994; Smith \& Quin 1996; Kinnear et al. 2002; Johnson 2006; Johnson et al. 2007; McKenzie et al. 2007; Burbidge et al. 2008). This differs from much of the rest of the world, where biodiversity decline is driven mostly by direct human exploitation, habitat loss from vegetation clearance and habitat fragmentation, and environmental degradation associated with human population growth (Wilcove et al. 1998; Sodhi et al. 2004; Cardillo et al. 2004, 2006).

The historical mammal extinctions did not occur in the monsoonal tropics of northern Australia, and this sparsely populated (human population density $<1$ person $10 \mathrm{~km}^{2}$ ), extensive (ca. 1.9 million $\mathrm{km}^{2}$ ), and largely natural vegetation cover $(<1 \%$ vegetation clearance in north-western Australia) region has been considered to provide a level of conservation security and environmental connectivity that is unusual on a global scale (Woinarski et al. 2007; Garnett et al. 2010). Hitherto, the maintenance of the region's native mammal fauna has been considered in part to arise because it has not been colonized by the red fox (McKenzie 1981; Smith \& Quin 1996).

However, the persistence of the region's native mammal fauna is now uncertain. Trends in the status of mammal fauna status have been difficult to define because the historical record is sparse and because monitoring has been limited and recent (Woinarski et al. 2004a; Start et al. 2007). Nonetheless, the few available considerations-based mostly on comparisons of current records with those of collectors from the late 19th and early 20th Centuries-describe local extinctions and declines for mammals in the lower rainfall (inland) fringes of northern Australia, including the south-west Kimberley (McKenzie 1981), south-east Kimberley (Kitchener 1978), and southern Top End of the Northern Territory (Johnson \& Southgate 1990; Woinarski 2000, 2004). Historical trends in north-eastern Australia (Queensland) have been less clear, but some declines in the mammal fauna of the savannas of Cape York Peninsula have been reported (Winter \& Allison 1980; Dickman et al. 2000; Kutt et al. 2005). These comparisons are constrained by imprecision about the timing of status change due to long intervals between the original and recent accounts of mammal assemblages, and the irregular sampling and qualitative assessments of abundance in the original accounts (e.g. Dahl 1897). Nonetheless, the general pattern, described in most detail for the Kimberley (McKenzie 1981), is of more (and/or earlier) decline from lower rainfall and topographically simple areas, with slowest decline in higher rainfall and rugged areas (McKenzie 1981; Woinarski 2000, 2004), and islands (Southgate et al. 1996; Woinarski et al. 1999a; Firth et al. 2006a). The limited information also suggests that north-western Australia has experienced the least declines, and has maintained populations of some species (e.g. golden bandicoot, Isoodon auratus; golden-backed tree-rat, Mesembriomys macrurus) that have disappeared from the Northern Territory (McKenzie 1981; Woinarski 2000). A notable feature of the pattern of northern mammal decline is that it has affected mostly the same types of species (larger dasyurids, larger rodents, smaller macropods, and bandicoots) that are relatively overrepresented in the set of extinct Australian mammals (see Fitzsimons et al. 2010 for a summary of mammal species in decline in northern Australia).

The broad historical contrasts, and more localized intensive monitoring studies, have recently been complemented by intensive demographic studies of individual mammal species exposed to experimental or prevailing management contrasts. In some cases (Pardon et al. 2003; Firth et al. 2010), the demographic data have been modeled, with results suggesting severe decline or extinction within the next 20 years.

Recently, we have also used another approachdocumentation of Indigenous knowledge-to seek a perspective on mammal status change with some historical depth and extent. Using mammal specimens displayed in life-like poses as props (following the protocol used by Burbidge et al. (1988) in central Australia), sometimes coupled with surveys resulting in captures of live animals, we sought information on changes in status of mammal species, from many remote Aboriginal communities across the Top End of northern Australia. Results 
from these sources (MZ unpubl. in Fitzsimons et al. 2010; Jones et al. 2010; Widijburru et al. 2010) consistently report extensive declines for some mammal species over the last few decades, with greater (and earlier) declines in lower rainfall areas, largely corroborating the more precise but more spatially limited record from the Kakadu monitoring program.

Another useful context for considering decline in north Australian mammals is the recent documentation of spatial and historical patterns of decline in the region's granivorous birds (Franklin 1999; Franklin et al. 2005), for which a more substantial database allows for more robust and comprehensive analysis. There are striking parallels, with trends for bird declines more marked in lower rainfall, flatter areas, and a progression of decline from east to west; however, the bird declines are less severe and lack recent acceleration. Franklin et al. (2005) attributed the bird declines to habitat change due to the progressive spread and impacts of livestock grazing and changed fire regimes.

\section{Causes}

The factors previously posited as driving mammal extinctions and declines elsewhere in Australia, and granivorous bird declines in northern Australia, are likely to be largely responsible for the current northern mammal declines. These factors might operate with differing relative impacts for different species and in different locations. The interplay of these factors is presented schematically in Figure 1. Broadly, we consider that there are only four possible proximate factors that may be directly causing the decline of the mammal fauna of northern Australia: habitat change, predation by feral cats, poisoning by cane toads (Bufo marinus: a meso-American amphibian that has spread rapidly from its point of introduction in north-eastern toward north-western Australia), and novel disease. In turn, these drivers are the consequence of three ultimate factors accompanying European settlement: loss of (continuity of) Indigenous land management in the remnant (mostly rugged and less productive) lands that were never converted to pastoralism, the transfer of other lands from traditional Indigenous management to pastoral land management, and the deliberate or inadvertent introductions of exotic plants and animals. Additional to this framework, there might be further gradual broad-scale environmental change in northern Australia attributable to climate change and the impacts of increased atmospheric $\mathrm{CO}_{2}$ concentration (Banfai \& Bowman 2006). The ultimate and proximate factors are linked through a series of intermediate mechanisms, described briefly here.
In areas of northern Australia that have remained Indigenous-owned, the relocation of most Aboriginal people from clan estates to a small number of large communities has resulted in the replacement of intensive and purposeful fire management, with regimes characterized by more extensive and intense fires, and reduced heterogeneity (Bowman et al. 2001; Russell-Smith et al. 2009). This has led to changes in vegetation structure and composition over extensive areas, most notably the depletion of a diverse woody understorey (Vigilante and Bowman 2004a,b; Vigilante et al. 2004; Atchison et al. 2005; Atchison 2009), that formerly provided much of the fleshy fruit resources required by some mammal species such as black-footed tree-rats and common brushtail possums, Trichosurus vulpecula (Friend \& Taylor 1985; Kerle 1985; Friend 1987), and a reduction in the abundance of large trees and tree hollows (Williams et al. 2003).

Over the last 100-150 years, pastoralism has become the primary land use across about $70 \%$ of northern Australia (Garnett et al. 2010). Grazing by cattle has directly caused some floristic change, but more substantially has contributed to various broad-scale changes in fire regimes, which has also promoted changes in vegetation structure and floristics (Woinarski et al. 1999b; Woinarski \& Ash 2002). In many nonpastoral areas, escaped stock (including cattle, Bos taurus; water buffalo, Bubalis bubalis; horse, Equus caballus, and donkey, Equus asinus) now occurs at densities comparable to managed stock, with similar environmental consequences (Bradshaw et al. 2007). Most pastoralism relies on native grasses but, increasingly, nonnative (mostly African) grass species have been introduced (and spread beyond pastoral lands: Preece et al. 2010); these radically alter understorey composition and structure, produce biomass far in excess of that of native grasses, and hence fuel fires of far greater intensity, exacerbating habitat degradation (Rossiter et al. 2003).

Pastoralism and changed fire regimes have led to extensive yet gradual and subtle changes in habitat structure that are far less severe than changes associated with clearing and fragmentation elsewhere in the world. If the habitat change in northern Australia has resulted in fragmentation of mammal populations, that fragmentation has been more diffuse and less apparent than in areas subjected to more intensive development.

In some pastoral regions, managers have also attempted to reduce populations of the top mammalian predator, the dingo, Canis lupus dingo; which might have led to increased feral cat abundance and predation pressure on small and medium-sized native mammals (Johnson et al. 2007). Feral cats have been present in northern Australia for more than 100 years (Abbott 


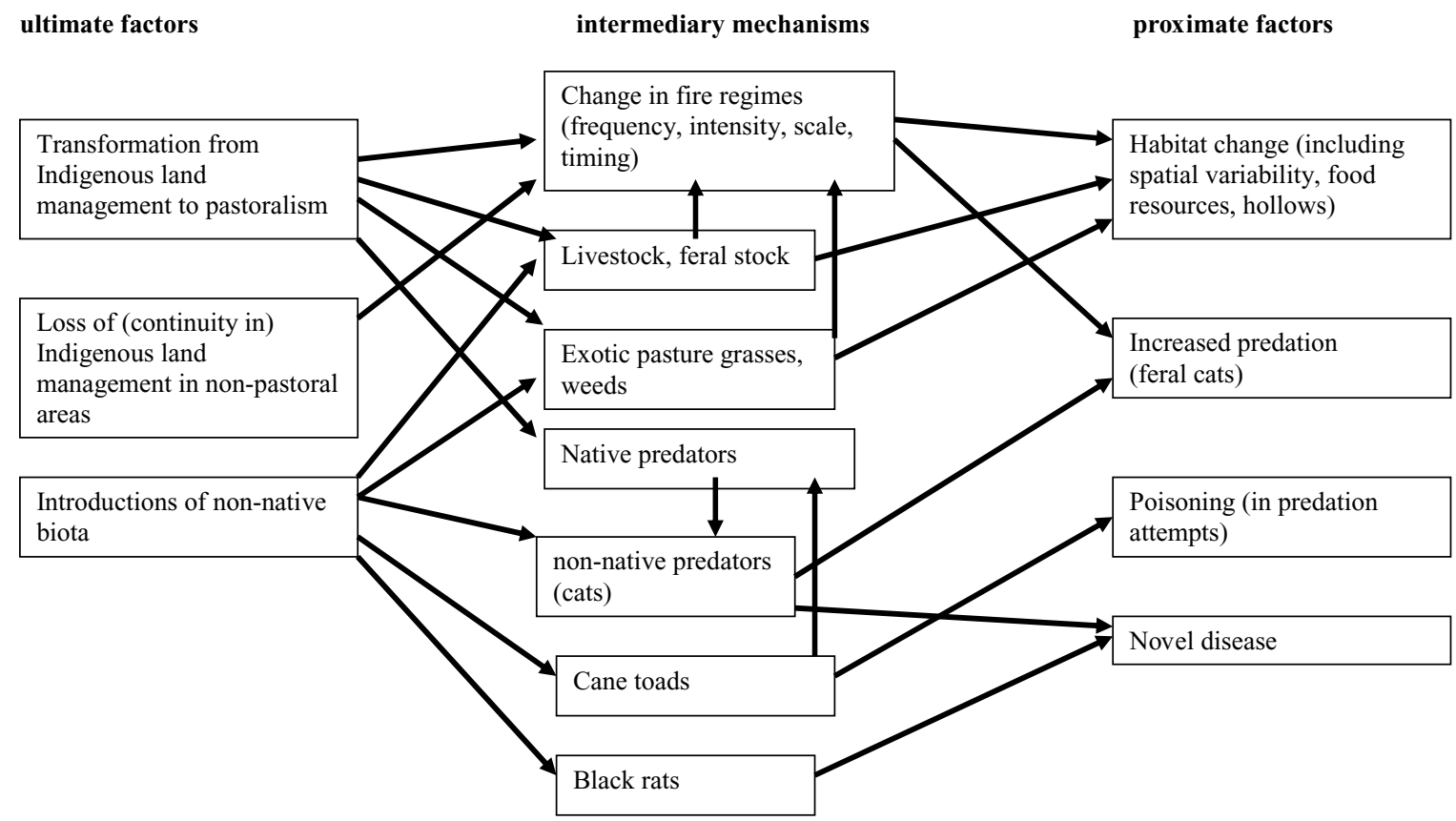

Figure 1 Schematic representation of the factors that might be driving the current decline in native mammals in northern Australia.

2002), but might have increased (in some areas) because of dingo reduction, and (in other areas) because cats were frequently transported to remote locations when some Aboriginal people returned to clan estates in the "outstation" movement of the 1960s (Woinarski 2005). Furthermore, cat predation can exacerbate the negative impacts of fire that removes many shelter sites for native mammals (Oakwood 2000).

Two other pests introduced to northern Australia have the potential for specific direct impacts on native mammal fauna. Cane toads have spread rapidly from their introduction point in north-eastern Queensland in the 1930s, colonized Kakadu in 2001, and their continued westward spread will see them occupy the entire north Australian mainland within another 10-20 years (Phillips et al. 2008). They can occur in large numbers, and their toxins cause mortality in some native predators, including the northern quoll, Dasyurus hallucatus (O'Donnell et al. 2010). Although the northern quoll was in decline across much of northern Australia (including Kakadu) prior to toad arrival (Braithwaite \& Griffiths 1994), its rate of decline has accelerated substantially. There is little evidence suggesting cane toads have caused declines in other native mammals, but they have caused reductions in some snake and monitor (goanna) species (Doody et al. 2009): such reductions in native predators might have benefited some native mammals, but could also have led to increases in the number of feral cats (through reduced competition and/or reduction in predation pressure by native predatory reptiles) (Ritchie $\&$ Johnson 2009).

Finally, it is possible that the native mammal decline is due to the effect of an introduced disease (Abbott 2006; Smith et al. 2008). There is no evidence for this argument, other than an observed increase in the Northern Territory in the prevalence and abundance of exotic black rats, Rattus rattus (known to be vectors for some diseases that have caused mammal extinctions elsewhere: Wyatt et al. 2008).

The evidence supporting each of these causal links is variable. The pattern of decline across species from a reasonably wide taxonomic and ecological range suggests that there might be multiple, interacting causes. The strongest evidence demonstrates that many mammal species are detrimentally affected by contemporary fire regimes (Pardon et al. 2003; Woinarski et al. 2004b; Firth et al. 2006b; Legge et al. 2008; Firth et al. 2010; Woinarski et al. 2010). There is reasonable support for negative impacts of pastoralism, as demonstrated by destocking experiments and cross-fence comparisons of grazed and ungrazed treatments (Woinarski \& Ash 2002; Legge et al. in press). There is unequivocal evidence demonstrating the marked negative impacts of toads on northern quolls (O'Donnell et al. 2010). Recent sampling for diseases from 100 black rats in the Kakadu and nearby area did not detect any novel disease likely to affect native mammals (B. Jackson pers. comm.). 
A notable feature of the Kakadu data over the last 20 years is the rapid rate and escalation of decline. This suggests a change in the threatening processes, or that mammal populations have passed a threshold in their capability to withstand ongoing or gradually increasing threats, and might have entered an extinction vortex. With the exception of the colonization and proliferation of toads in Kakadu, there is no direct evidence of marked change in the threat environment there over the period of this monitoring program; while toads have clearly affected one native mammal species, it is not plausible that they have had such large, direct impacts on so many diverse mammal species. Thus, on the available evidence, there is no straightforward single explanation of this marked recent decline. The relatively gradual rate of habitat change appears to be inconsistent with the marked rate of recent mammal decline; the impacts of toads appear to be limited to one or few mammal species; as yet there is only anecdotal information about recent changes in the abundance of feral cats and the severity of their impacts; fire patterns have not become markedly more severe in recent years (Price et al. 2005), the density of introduced herbivores has not changed much, and a recently established study did not identify any evidence to support the role of novel diseases. Consistent with many studies elsewhere (Brook 2008; Brook et al. 2008; Davidson et al. 2009), impacts might be compounded by multiple coincident threatening factors.

\section{Responses}

There is a linked research and management response to this biodiversity decline. For research, the most pressing requirement is to identify the principal cause and interactive pathways of the decline. Of the four proximate factors in Figure 1, we have a reasonable understanding of the role and workings of habitat change; recent studies have advanced knowledge of the role and impacts of cane toads; and studies currently underway are suggesting that disease is not likely to be the principal driver. In contrast, our knowledge of the abundance, ecology, and impact of feral cats in northern Australia is particularly limited. Hence, the research priority is to (1) assess the impacts of cats on native mammal fauna, particularly through experimental contrasts using cat exclosure fencing; (2) identify mechanisms that might account for a possible recent increase in the prevalence of cats or a recent exacerbation of their impacts on native mammals; (3) assess the extent to which the impacts of predation by cats might be affected by other factors, most notably fire regime; and (4) identify practical and costeffective management responses for the difficult problem of broad-scale control of feral cats. This research agenda should provide definitive evidence about the extent to which feral cats are driving the native mammal decline, a distinction that has been difficult to determine in many comparable situations elsewhere, but one which is critical for the effectiveness of any management response (Gurevitch \& Padilla 2004; Ricciardi 2004).

One other main priority, which bridges research and management, is to establish monitoring programs more representatively across northern Australia, wherever possible tied to the measurement of the effectiveness of management interventions. This will require a long-term commitment from different levels of government and land-management agencies.

Management responses must be both policy related and operational. In this largely "natural" landscape, policy should embed explicit obligation on all landholders to maintain biodiversity, and seek broad-scale management that is coordinated across all tenures. For existing conservation reserves, the obligation to conserve biodiversity should be hard-wired into management planning, performance measurement, and resourcing (Parr et al. 2009).

There has been policy development in recent years relating to regulation of the introduction and deliberate spread of nonnative biota (in this case, particularly invasive pasture grasses), but the continuing range expansion of many invasive species outstrips or eludes policy advance.

The pastoral industry remains a dominant force in northern Australia, although there is a recent trend, especially in the nongovernment sector, to manage pastoral lands for conservation purposes (e.g., by removing stock and implementing fire management with explicit ecological objectives), and to develop cooperative arrangements to manage parts of their properties for conservation outcomes. There is scope for this to be further developed.

On Indigenous lands, recent policy development has resulted in a substantial growth of local ranger schemes and the creation of Indigenous Protected Areas (Gilligan 2006). Over the last two decades, these have expanded the conservation reserve system in the region from 6 to $10 \%$ (Garnett et al. 2010). In some cases, resourcing for these schemes has been supplemented by carbon funding arising from more benign fire management, but the policy setting for such carbon funding remains unsettled and limited.

Regardless of the policy context, for biodiversity there is a clear practical requirement to manage fire more effectively, particularly to reduce fire extent and intensity over large landscapes, and to increase heterogeneity (fire patchiness) and the extent and proportion of longer unburnt habitat. 
Finally, as is the case in other regions of Australia, the islands of northern Australia provide a considerable conservation refuge (largely because many are uninhabited and/or have none or few of the threats that are pervasive on mainland areas), and require explicit management consideration. Most are Aboriginal owned, and policy and management needs to be developed collaboratively. For example, there is currently no regulation relating to the introduction of cats to these islands, not withstanding the recent demonstration of the rapid local extinction of native mammals following the introduction of cats to islands in the Sir Edward Pellew group of northern Australia (Woinarski et al. unpubl. data).

\section{Conclusions and global consideration}

Our assessment of declines over the last decades in the mammal fauna of Kakadu is that they are a delayed reverberation of the wholesale shift in land management in Australia following European colonization in 1788 (with later--mostly 1850s to 1890s-imposition in northern Australia). In northern Australia, the ecological shifts have been relatively subtle and gradual-the land remains largely "natural" in appearance and composition. Many mammal species have declined gradually but extensively, but might now have passed a threshold where a combination of threatening factors of increasing intensity renders their decline more precipitous and their persistence unlikely. The landscape now presents another variant on the "empty forest" situation (Redford 1992), where a superficially intact habitat is losing key components of its biodiversity.

Recent global assessments of the fate of biodiversity document alarming declines, associated particularly with extensive habitat clearance and fragmentation, and/or direct exploitation, especially in regions subject to rapid human population growth. In the face of such decline, a major response has been to seek to maintain extensive natural areas and to establish large conservation reserves. In this context, the current rapid decline of mammals in Kakadu National Park is especially troubling because it suggests that the fate of biodiversity might be even bleaker than evident in recent reviews (McKibben 2006); and that, while necessary, the establishment of conservation reserves alone is clearly insufficient to maintain biodiversity. This latter conclusion is not new (Liu et al. 2001; Rodrigues 2006; Brashares 2010; Karanth et al. 2010); but the results we report emphasize the need to manage reserves (and their threats, and their surrounds) far more intensively, purposefully, and effectively.

\section{Acknowledgements}

Our work has been supported by many agencies, funding bodies, and landholders, but we acknowledge specifically Parks Australia, the Tropical Savannas Cooperative Research Center, the Australian Wildlife Conservancy, and Australia Research Council Linkage Grants (LP0455163, LP0561555 and LP100100033).

\section{References}

Abbott, I. (2002) Origin and spread of the cat, Felis catus, on mainland Australia, with a discussion of the magnitude of its early impact on native fauna. Wildl Res 29, 51-74.

Abbott, I. (2006) Mammalian faunal collapse in Western Australia, 1875-1925: the hypothesised role of epizootic disease and the conceptual model of its origin, introduction, transmission and spread. Aust Zool 33, 530-561.

Atchison, J. (2009) Human impacts on Persoonia falcata. Perspectives on post-contact vegetation change in the Keep River region, Australia, from contemporary vegetation surveys. Veget Hist Archaeobot 18, 147-157.

Atchison, J., Head L., Fullagar R. (2005) Archaeobotany of fruit seed processing in a monsoon savanna environment: evidence from the Keep River region, Northern Territory, Australia. J Archaeol Sci 32, 167-181.

Baillie, J. (1996) Analysis. Pages 24-41 in J. Baillie \& B. Roombridge, editors. IUCN Red List of threatened animals. IUCN, Gland.

Banfai, D.S., Bowman D.M.J.S. (2006) Forty years of lowland monsoon rainforest expansion in Kakadu National Park, northern Australia. Biol Conserv 131, 553-565.

Bowman, D.M.J.S., Price O., Whitehead P.J., Walsh A. (2001) The 'wilderness effect' and the decline of Callitris intratropica on the Arnhem Land Plateau, Northern Australia. Aust J Bot 49, 665-672.

Bradshaw, C.J.A., Field I.C., Bowman D.M.J.S., Haynes C., Brook B.W. (2007) Current and future threats from non-indigenous animal species in northern Australia: a spotlight on World Heritage Area Kakadu National Park. Wildl Res 34, 419-436.

Braithwaite, R.W., Griffiths A. (1994) Demographic variation and range contraction in the northern quoll Dasyurus hallucatus (Marsupialia: Dasyuridae). Wildl Res 21 , 203-217.

Brashares, J.S. (2010) Filtering wildlife. Science 329, 402-403. Brook, B.W. (2008) Synergies between climate change, extinctions and invasive vertebrates. Wildl Res 35, 249-252.

Brook, B.W., Sodhi N.S., Bradshaw C.J.A. (2008) Synergies among extinction drivers under global change. Trends Ecol Evol 23, 453-460.

Burbidge, A.A., Johnson K.A., Fuller P.F., Southgate R.I. (1988) Aboriginal knowledge of mammals of the central deserts of Australia. Aust Wildl Res 15, 9-39. 
Burbidge, A.A., McKenzie N.L. (1989) Patterns in the modern decline of Western Australia's vertebrate fauna: causes and conservation implications. Biol Conserv 50, 143-198.

Burbidge, A.A., McKenzie N.L., Brennan K.E.C. et al. (2008) Conservation status and biogeography of Australia's terrestrial mammals. Aust J Zool 56, 41 1-422.

Calaby, J.H. (1973) Mammals. In Alligator Rivers region environmental fact-finding study. CSIRO Division of Wildlife Research, Canberra.

Cardillo, M., Bromham L. (2001) Body size and risk of extinction in Australian mammals. Conserv Biol 15, 1435-1440.

Cardillo, M., Purvis A., Sechrest W., Gittleman J.L., Bielby J., Mace G.M. ( 2004) Human population density and extinction risk in the world's carnivores. PLoS Biol 2, 909-914.

Cardillo, M., Mace G.M., Gittleman J.L., Purvis A. (2006) Latent extinction risk and the future battlegrounds of mammal conservation. Proc Natl Acad Sci USA 103, 4157-4161.

Chisholm, R., Taylor R. (2007) Null-hypothesis significance testing and the critical weight range for Australian mammals. Conserv Biol 21, 1641-1645.

Dahl, K. (1897) Biological notes on north-Australian mammalia. Zoologist, Series 4, 1, 189-216.

Davidson, A.D., Hamilton M.J., Boyer A.G., Brown J.H., Ceballos G. (2009) Multiple ecological pathways to extinction in mammals. Proc Natl Acad Sci 106, 10702-10705.

Dickman, C.R., Leung L.K.-P., Van Dyck S.M. (2000) Status, ecological attributes and conservation of native rodents in Queensland. Wildl Res 27, 333-346.

Doody, J.S., Green B., Rhind D., Castellano R., Simms R., Robinson T. (2009) Population-level declines in Australian predators caused by an invasive species. Anim Conserv 12, 46-53.

Edwards, A., Kennett R., Price O., Russell-Smith J., Spiers G., Woinarski J.C.Z. (2003) Monitoring the impacts of fire regimes on biodiversity in northern Australia: an example from Kakadu National Park. Int J Wildland Fire 12, 427-440.

Finlayson H.H. (1945) The Red Centre - Man and Beast in the Heart of Australia. Angus and Robertson, Sydney.

Finlayson, H.H. (1961) On central Australian mammals, Part IV. The distribution and status of central Australian species. Rec South Aust Mus 41, 141-191.

Firth, R.S.C., Woinarski J.C.Z., Brennan K.G., Hempel C. (2006a) Environmental relationships of the brush-tailed rabbit-rat Conilurus penicillatus and other small mammals on the Tiwi Islands, northern Australia. J Biogeog 33, 1820-1837.

Firth, R.S.C., Woinarski J.C.Z., Noske R.A. (2006b) Home range and den characteristics of the brush-tailed rabbit-rat (Conilurus penicillatus) in the monsoonal tropics of the Northern Territory, Australia. Wildl Res 33, 397-407. Firth, R.S.C., Brook B.W., Woinarski J.C.Z., Fordham D.A.
(2010) Decline and likely extinction of a northern Australian native rodent, the Brush-tailed Rabbit-rat Conilurus penicillatus. Biol Conserv 143, 1193-1201.

Fitzsimons, J., Legge S., Traill B., Woinarski J. (2010) Into Oblivion? The disappearing native mammals of Northern Australia. The Nature Conservancy, Melbourne.

Franklin, D.C. (1999) Evidence of disarray amongst granivorous bird assemblages in the savannas of northern Australia, a region of sparse human settlement. Biol Conserv 90, 53-68.

Franklin, D.C., Whitehead P.J., Pardon G., Matthews J., McMahon P., McIntyre D. (2005) Geographic patterns and correlates of the decline of granivorous birds in northern Australia. Wildl Res 32, 399-408.

Friend, G.R. (1987) Population ecology of Mesembriomys gouldii (Rodentia: Muridae) in the wet-dry tropics of the Northern Territory. Aust Wildl Res 12, 151-162.

Friend, G.R., Taylor J.A. (1985) Habitat preferences of small mammals in tropical open-forest of the Northern Territory. Aust J Ecol 10, 173-185.

Garnett, S.T., Woinarski J.C.Z., Crowley G.M., Kutt A.S. (2010) Biodiversity conservation in Australian tropical rangelands. Pages 189-234 in J. du Toit, R. Kock, J. Deutsch, editors. Wild Rangelands: conserving wildife while maintaining livestock in semi-arid ecosystems. Blackwell, London.

Gilligan, B. (2006) The Indigenous protected area programme-2006 evaluation. Department of the Environment and Heritage, Canberra.

Gurevitch, J., Padilla D. K. (2004) Are invasive species a major cause of extinctions? Trends Ecol Evol 19, 470-474.

Johnson, C. (2006) Australia's Mammal Extinctions: a 50,000 year history. Cambridge University Press, Melbourne.

Johnson, C.N., Isaac J.L. (2009) Body mass and extinction risk in Australian marsupials: the 'critical weight range' revisited. Aust Ecol 34, 35-40.

Johnson C.N., Isaac J.L., Fisher D.O. (2007) Rarity of a top predator triggers continent-wide collapse of mammal prey: dingoes and marsupials in Australia. Proc Roy Soc B 274, 341-346.

Johnson, K.A., Southgate R.I. (1990) Present and former status of bandicoots in the Northern Territory. Pages 85-92 in J.H. Seebeck, P.R. Brown, R.I. Wallis, C.M. Kemper, editors. Bandicoots and Bilbies. Surrey Beatty \& Sons, Sydney.

Jones, J.M., Bardbarriya D., Raymond E. et al. (2010) Jaminjung, Ngaliwurru and Nungali Plants and Animals: Aboriginal knowledge of flora and fauna from the Bradshaw, Gregory National Park and Timber Creek Area, North Australia. Northern Territory Department of Natural Resources, Environment, The Arts and Sport, Darwin.

Karanth, K.K., Nichols J.D., Karanth K.U., Hines J.E., Christensen Jr N.L. (2010) The shrinking ark: patterns of large mammal extinctions in India. Proc Roy Soc B 277, 1971-1979. 
Kerle, J.A. (1985) Habitat preference and diet of the northern brushtail possum Trichosurus vulpecula in the Alligator Rivers region, N.T. Proc Ecol Soc Aust 13, 161-176.

Kinnear, J.E., Sumner N.R., Onus M.L. (2002) The red fox in Australia: an exotic predator turned biocontrol agent. Biol Conserv 108, 335-359.

Kitchener, D.J. (1978) Mammals of the Ord River area, Kimberley, Western Australia. Rec Western Aust Mus 6 , 189-217.

Kutt, A.S., Bolitho E.E., Retallick R.W.R., Kemp J.E. (2005) Pattern and change in the terrestrial vertebrate fauna of the Pennefather River, Gulf of Carpentaria, Cape York Peninsula. Pages 261-300 in Gulf of Carpentaria Scientific Study Report. Geography Monograph Series No. 10, Royal Geographical Society of Queensland Inc., Brisbane.

Legge, S., Kennedy M., Lloyd R., Murphy S., Fisher A. (in press) Rapid recovery of mammal fauna in the central Kimberley, northern Australia, following the removal of introduced herbivores. Austral Ecol.

Legge, S., Murphy S., Heathcote J., Flaxman E., Augusteyn J., Crossman M. (2008) The short-term effects of an extensive and high-intensity fire on vertebrates in the tropical savannas of the central Kimberley, northern Australia. Wildl Res 35, 33-43.

Liu, J., Linderman M., Ouyang Z., An L., Yang J., Zhang H. (2001) Ecological degradation in protected areas: the case of Wolong Nature Reserve for giant pandas. Science 292, 98-101.

McKenzie, N.L. (1981) Mammals of the Phanerozoic south-west Kimberley, Western Australia: biogeography and recent changes. $J$ Biogeog 8, 263-280.

McKenzie, N.L., Burbidge A.A., Baynes A. et al. (2007) Analysis of factors implicated in the recent decline of Australia's mammal fauna. J Biogeog 34, 597-611.

McKibben, B. (2006) The End of Nature. Random House, New York.

Morton, S.R. (1990) The impact of European settlement on the vertebrate animals of arid Australia: a conceptual model. Proc Ecol Soc Aust 16, 210-213.

Oakwood M. (2000) Reproduction and demography of the northern quoll, Dasyurus hallucatus, in the lowland savanna of northern Australia. Aust J Zool 48, 519-539.

O’Donnell, S., Webb J.K., Shine R. (2010) Conditioned taste aversion enhances the survival of an endangered predator imperiled by a toxic invader. J Appl Ecol 47, 558-565.

Pardon, L.G., Brook B.W., Griffiths A.D., Braithwaite R.W. (2003) Determinants of survival for the northern brown bandicoot under a landscape-scale fire experiment. J Anim Ecol 72, 106-115.

Parr, C.L., Woinarski J.C.Z., Pienaar D.J. (2009) Cornerstones of biodiversity conservation? Comparing the management effectiveness of Kruger and Kakadu National Parks, two key savanna reserves. Biod Conserv 18, 3643-3662.

Phillips, B.L., Chipperfiled J.D., Kearney M.R. (2008) The toad ahead: challenges of modeling the range and spread of an invasive species. Wildl Res 35, 222-234.

Preece, N., Harvey K., Hempel C., Woinarski J.C.Z. (2010) Uneven distribution of weeds along extensive transects in Australia's Northern Territory points to management solutions. Ecol Man Rest 11, 127-134.

Price, O., Edwards A., Connors G. et al. (2005) Fire heterogeneity in Kakadu National Park, 1980-2000. Wildlife Research 32, 425-433.

Redford, K.H. (1992) The empty forest. BioScience 42 , 412-422.

Ricciardi, A. (2004) Assessing species invasions as a cause of extinction. Trends Ecol Evol 19, 619.

Ritchie, E.G., Johnson C.N. (2009) Predator interactions, mesopredator release and biodiversity conservation. Ecol Letters 12, 982-998.

Rodrigues, A.S.L. (2006) Are global conservation efforts successful? Science 313, 1051-1052.

Rossiter, N.A., Setterfield S.A., Douglas M.M., Hutley L.B. (2003) Testing the grass-fire cycle: alien grass invasion in the tropical savannas of northern Australia. Diversity Distrib 9, 169-176.

Russell-Smith, J., Whitehead P.J., Cooke P. editors. (2009) Culture, ecology and economy of fire management in Northern Australia: rekindling the Wurrk Tradition. CSIRO Publishing, Melbourne.

Short, J., Smith A. (1994) Mammal decline and recovery in Australia. J Mammal 75, 288-297.

Smith, A.P., Quin D.G. (1996) Patterns and causes of extinction and decline in Australian conilurine rodents. Biol Conserv 77, 243-267.

Smith, A., Clark P., Averis S. et al. (2008) Trypanosomes in a declining species of threatened Australian marsupial, the brush-tailed bettong Bettongia penicillata (Marsupialia: Potoridae). Parasitology 135, 1329-1335.

Sodhi, N.S., Koh L.P., Brook B.W., Ng P.K.L. (2004) Southeast Asian biodiversity: the impending disaster. Trends Ecol Evol 19, 654-660.

Southgate, R., Palmer C., Adams M., Masters P., Triggs B., Woinarski J. (1996) Population and habitat characteristics of the Golden Bandicoot (Isoodon auratus) on Marchinbar Island, Northern Territory. Wildl Res 23, 647-664.

Start, A.N., Burbidge A.A., McKenzie N.L., Palmer C. (2007) The status of mammals in the North Kimberley, Western Australia. Aust Mammal 2, 1-16.

Vigilante, T., Bowman D.M.J.S. (2004a) Effects of fire history on the structure and floristic composition of woody vegetation around Kalumburu, North Kimberley, Australia: a landscape-scale natural experiment. Aust J Bot 52, 381-404.

Vigilante, T., Bowman D.M.J.S. (2004b) Effects of individual fire events on the flower production of fruit-bearing tree species, with reference to aboriginal people's management and use, at Kalumburu, North Kimberley, Australia. Aust J Bot 52, 405-415. 
Vigilante, T., Bowman D.M.J.S., Fisher R., Russell-Smith J., Yates C. (2004) Contemporary landscape burning patterns in the far north Kimberley region of north-west Australia: human influences and environmental determinants. $J$ Biogeogr 31, 1317-1333.

Widijburru, B., Harrington D., Balwanjer R. et al. (2010) Ngarinyman plants and animals. Aboriginal knowledge of flora and fauna from Judburra/Gregory National Park and the Victoria River District area, northern Australia. Northern Territory Department of Natural Resources, Environment, The Arts and Sport, Darwin.

Wilcove, D.S., Rothstein D., Dubow J., Phillips A., Losos E. (1998) Quantifying threats to imperiled species in the United States: assessing the relative importance of habitat destruction, pollution, overexploitation, and disease. BioScience 48, 607-615.

Williams, R.J., Muller W.J., Wahren C-H., Setterfield S.A., Cusack J. (2003) Vegetation Pages 79-106 in A.N. Andersen, G.D. Cook, RJ Williams, editors. Fire in tropical savannas. The Kapalga experiment. Springer-Verlag, New York.

Winter, J.W, Allison F.R. (1980) The native mammals of Cape York Peninsula: changes in status since the 1948 Archbold Expedition. Pages 31-47 in N.C. Stevens, A. Bailey, editors. Contemporary Cape York. Royal Society of Queensland, Brisbane.

Woinarski, J.C.Z. (2000) The conservation status of rodents in the monsoonal tropics of the Northern Territory. Wildl Res 27, 421-435.

Woinarski, J.C.Z. (2004) In a land with few possums, even the common are rare: ecology, conservation and management of possums in the Northern Territory. Pages 51-62 in R. Goldingay, S. Jackson, editors. The biology of Australian possums and gliding possums. Surrey Beatty $\&$ Sons, Sydney.

Woinarski, J.C.Z. (2005) A difficult and destructive metamorphosis: conservation and land management in the Northern Territory in the 1950s. Pages 33-55 in J.T. Wells, M. Dewar, S. Parry, editors. Modern Frontier: aspects of the 1950s in Australia's Northern Territory. Charles Darwin University Press, Darwin.

Woinarski, J.C.Z., Ash A.J. (2002) Responses of vertebrates to pastoralism, military land use and landscape position in an Australian tropical savanna. Aust Ecol 27, 311-323.

Woinarski, J.C.Z., Palmer C., Fisher A., Southgate R., Masters P., Brennan K. (1999a) Distributional patterning of mammals on the Wessel and English Company islands, Arnhem Land, Northern Territory, Australia. Aust J Zool 47, 87-111.

Woinarski, J.C.Z., Brock C., Fisher A., Milne D., Oliver B. (1999b) Response of birds and reptiles to fire regimes on pastoral land in the Victoria River District, Northern Territory. Rangel J 21, 24-38.

Woinarski, J.C.Z., Milne D.J., Wanganeen G. (2001) Changes in mammal populations in relatively intact landscapes of Kakadu National Park, Northern Territory, Australia. Austral Ecol 26, 360-370.

Woinarski, J.C.Z., Armstrong M., Price O., McCartney J., Griffiths, T., Fisher A. (2004a) The terrestrial vertebrate fauna of Litchfield National Park, Northern Territory: monitoring over a 6-year period, and response to fire history. Wildl Res 31, 1-10.

Woinarski, J.C.Z., Risler J., Kean L. (2004b) The response of vegetation and vertebrate fauna to 23 years of fire exclusion in a tropical Eucalyptus open forest, Northern Territory, Australia. Aust Ecol 29, 156-176.

Woinarski, J.C.Z., Mackey B., Nix H., Traill B. (2007) The Nature of Northern Australia: natural values, ecological processes and future prospects. ANU e-press, Canberra.

Woinarski, J.C.Z., Armstrong M., Brennan K. et al. (2010) Monitoring indicates rapid and severe decline of native small mammals in Kakadu National Park, northern Australia. Wildl Res 37, 116-126.

Wyatt, K.B., Campos P.F., Gilbert M.T.P. et al. (2008) Historic mammal extinction on Christmas Island (Indian Ocean) correlates with introduced infectious disease. PLOS ONE 3(11), e3602. 